\title{
REVISITANDO A BASE DE CONHECIMENTOS E O CONHECIMENTO PEDAGÓGICO DO CONTEÚDO (PCK) DE PROFESSORES DE CIÊNCIAS
}

\author{
Carmen Fernandez 1;*
}

RESUM0: A literatura, em especial da área de ensino de ciências, tem apontado uma base de conhecimentos para professores que delimita e caracteriza essa profissão. Dentre estes, o Conhecimento Pedagógico do Conteúdo (PCK, na sigla em inglês), representa o conhecimento que os professores utilizam no processo do ensino, distinguindo o professor de uma dada disciplina de um especialista dessa disciplina e tem sido considerado um modelo frutífero para a investigação sobre os professores de ciências e, para subsidiar currículos e propostas de formação inicial e contínua. Por outro lado, existe pouca literatura em português e, a julgar pela sua importância no cenário internacional e pelo problema com as traduções de alguns termos, justifica-se fornecer um panorama da literatura em ensino de ciências apresentando os componentes da base de conhecimentos de professores e, em particular, o PCK, os modos estabelecidos para seu acesso, além de apresentar uma análise crítica aos modelos propostos. Palavras-chave: Base de conhecimentos para professores. Conhecimento pedagógico do conteúdo. Ensino de ciências.

\section{REVISITING THE KNOWLEDGE BASE AND SCIENCE TEACHERS' PEDAGOGICAL CONTENT KNOWLEDGE}

ABSTRACT: The literature, especially in science teaching has appointed a professional knowledge base for teaching, which defines and characterise the teaching profession. Among these, the Pedagogical Content Knowledge (PCK) represents the knowledge that teachers use in the educational process and distinguishes a teacher of a given discipline from an expert of that discipline and has been considered a fruitful model for research on science teachers and for support curricula and proposals for initial and continuing training. On the other hand, there is little literature in Portuguese and, judging its importance in the international scene and the problems with translations of some terms, an overview of the literature on science education presenting the components of the knowledge base and PCK, the models set for its access and its documentation is justified. The paper also presents a critical analysis of the proposed models.

Keywords: Knowledge base for teachers. Pedagogical content knowledge, Science education.

\author{
* Doutora em Química pela \\ Universidade de São Paul \\ (USP-SP). Professora associada \\ do Departamento de Química \\ Fundamental, Instituto de Química \\ da USP. Orientadora credenciada \\ no Programa de Pós-Graduação \\ Interunidades em Ensino de Ciências \\ da USP. Coordenadora do Grupo \\ PEQuim (Pesquisa em Ensino de \\ Química) \\ E-mail: carmen@iq.usp.br \\ 1. Universidade de São Paulo \\ (USP-SP), São Paulo/SP, Brasil
}

DOI - http://dx.doi.org/10.1590/1983-21172015170211 
RESUMEN: La literatura, en especial en el área de la enseñanza de ciencias, apunta a una base de conocimientos de maestros que delimita y identifica esa profesión. Dentre ellos, el Conocimiento Pedagógico del Contenido (PCK en la sigla en inglés), representa el conocimiento que los maestros utilizan en el proceso de enseñanza, que distingue un maestro de una disciplina de un especialista de esa disciplina y ha sido considerado un modelo fructífero para la investigación acerca de los maestros de ciencias y, para subsidiar currículos y propuestas de formación inicial y continua. Por otro lado, existe poca literatura en portugués y, a juzgar por su importancia en el escenario internacional, y por el problema con las traducciones de algunos términos, justificase un panorama de la literatura en la enseñanza de ciencias presentando los componentes de la base de conocimientos de maestros y, en particular, del PCK y los modos establecidos para para el acceso. Además, presentamos un análisis crítica de los modelos propuestos Palabras clave: Conocimiento base para la enseñanza. Conocimiento Pedagógico del Contenido. Enseñanza de Ciencias. 


\section{INTRODUÇÃO}

O ensino como uma profissão implica um campo de conhecimentos que possa ser sistematizado e assim comunicado a outros (SHULMAN, 2004). Toda profissão possui um corpo de conhecimentos característico, que a delimita e identifica seus agentes como possuidores desses conhecimentos e, assim, garante que possam exercê-la perante a sociedade (MARCELO, 2005). Entretanto, uma ideia de senso comum bastante difundida é a de que para ser professor basta conhecer algum conteúdo. Na prática, entretanto, não é só isso que caracteriza um bom professor. Se assim fosse, todos os professores universitários, pesquisadores e especialistas em seu conteúdo, deveriam ser excelentes professores. No entanto, é sabido que essa não é em absoluto uma verdade e, pelo contrário, a ineficiência dos especialistas na sala de aula é uma das grandes queixas dos estudantes nas universidades de modo geral. Embora o conhecimento do conteúdo específico seja primordial na tarefa de ser professor, seu domínio é apenas parte da história, uma vez que habilidades específicas para o ensino são, há muito, reconhecidas como necessárias (KIND, 2009).

A falta de sistematização dos conhecimentos necessários à profissão docente faz dela muitas vezes uma atuação temporária de outros profissionais. E essa falta de sistematização tem sido amplamente combatida pelos investigadores da área (SHULMAN, 2004).

A origem do programa de pesquisa sobre os conbecimentos dos professores (teachers knowledge) data de 1968 no congresso do Instituto Nacional de Educação (GAGE, 1975). Nesse congresso, Lee Shulman coordenou um dos painéis cujo objetivo era descrever a vida mental dos professores e, ao final, os participantes concordaram em conceber o professor como um agente que toma decisões, reflete, emite juízos, possui crenças, atitudes, entre outras posturas (MARCELO, 1987).

Segundo Shulman (2004), o caminho que as pesquisas sobre professores têm percorrido se inicia sobre o ensino eficaz e que pode ser medido através do resultado produzido nos alunos; tendo como marco conceitual o processo-produto. Nesse paradigma, a ideia era que os professores deviam seguir programas e metodologias investigados e testados na academia e eram tratados como meros reprodutores de um programa de ensino desenvolvido por alguém mais capaz.

Na sequência, a partir da disseminação da vertente cognitivista, somada à aceitação de enfoques mais interpretativos e metodologias qualitativas, desenvolve-se o paradigma mediacional centrado no professor, a partir dos anos 1980, e conhecido como conhecimento dos professores. Nesse programa, investigações sobre planejamento do professor, decisões, diagnósticos, reflexão e resolução de problemas passaram a dominar a agenda das pesquisas.

\section{Conhecimentos ou saberes de professores}

$\mathrm{Na}$ vasta literatura sobre conhecimento de professores é possível identificar duas linhas dominantes: uma linha que se aproxima dos estudos de Shulman 
(1986, 1987) que operam, sobretudo, pela desmontagem analítica dos componentes envolvidos no conhecimento docente (conhecimento do conteúdo, conhecimento do currículo, conhecimento dos alunos, conhecimento pedagógico do conteúdo e conhecimento pedagógico); e outra segue a linha de Elbaz (1983) e Connelly e Clandinin (1985), da corrente teórica do "pensamento do professor" desenvolvida sob a forte influência de Schön e da sua epistemologia da prática; se centra na construção do conhecimento profissional como processo de elaboração reflexiva a partir da prática do profissional em ação (ROLDÃO, 2007). A distinção entre conhecimentos e crenças de professores nem sempre é clara na pesquisa ou concordante entre vários pesquisadores (FENSTERMACHER 1994).

$\mathrm{Na}$ linha de Shulman, ganha destaque entre os conhecimentos docentes o Conhecimento Pedagógico do Conteúdo (PCK, da expressão em inglês, Pedagogical Content Knowledge) que, segundo o autor, representaria o conhecimento profissional de professores, algo que distinguiria um professor de uma dada disciplina de um especialista dessa mesma disciplina. $\mathrm{O}$ uso da sigla em inglês se justifica pelo fato de ela já ser tão conhecida na literatura que é tratada como sinônimo do próprio conceito.

No Brasil os referenciais dos saberes da prática e/ou saberes dos professores têm sido mais utilizados - através da difusão dos textos em português de Tardif et al. (1991); Gauthier et al. (1998); Tardif (2010); Pimenta (2012); Tardif e Lessard (2013) entre outros, que seguem a corrente teórica do "pensamento do professor".

Os termos saberes e conhecimentos, apesar de muitas vezes serem usados como sinônimos, provêm de correntes teóricas distintas. Segundo Fiorentini, Souza Júnior e Melo (1998) ao tratar de saberes e conhecimentos:

[...] o conhecimento aproximar-se-ia mais com a produção científica sistematizada e acumulada historicamente com regras mais rigorosas de validação tradicionalmente aceitas pela academia; o saber, por outro lado, representaria um modo de conhecer/saber mais dinâmico, menos sistematizado ou rigoroso e mais articulado a outras formas e fazer relativos à prática não possuindo normas rígidas formais de validação. (FIORENTINI, SOUZA JÚNIOR; MELO, 1998, p. 312)

E Geraldi (2003, p. 18) define os saberes:

[...] enquanto um conjunto de práticas sociais, que não chegam à sistematização, mas orientam nossos juízos e muitas de nossas ações cotidianas. Deste modo, enquanto "o saber é produto das práticas sociais, o conhecimento é a organização desse produto das práticas sociais de forma sistemática, racional, na atividade científica".

Para Roldão (2007), a necessidade de se teorizar e estudar o conhecimento profissional se dá, dentre outras razões, pois: 
A atividade de ensinar - como sucedeu com outras atividades profissionais - praticou-se muito antes de sobre ela se produzir conhecimento sistematizado. Estas profissões transportam por isso uma inevitável "praticidade" que, a não ser questionada/teorizada, jamais transformaria a atividade em ação profissional e mantê-la-ia prisioneira de rotinas não questionadas e incapazes de responder à realidade. [...] a progressiva teorização da ação, neste como noutros domínios, foi gerando, por sua vez, novos corpos de conhecimento, que passam a alimentar - e a transformar - a forma de agir dos profissionais em causa. (ROLDÃO, 2007, p. 97)

$\mathrm{Na}$ literatura sobre conhecimento dos professores, várias denominações têm sido utilizadas, dependendo da orientação teórica da época. Entre elas, estão conhecimento artesão, conhecimento prático pessoal, saberes da prática, conhecimento em ação, conhecimento pessoal (CONNELLY; CLANDININ, 1985), conhecimento situado, conhecimento artesão profissional, conhecimento tácito, entre outras (ABELL, 2007).

Pelos trechos apresentados, depreende-se que conhecimento é distinto de saber e não é sem razão que Shulman nomeia de "conhecimento de professores" seu programa de pesquisa, pois o que se busca é a valorização da atividade profissional dos professores elevando-a a um espaço de transformação e construção de conhecimentos específicos para a profissão. Assim, o conhecimento é a especialização do saber, ou seja, o conhecimento passa pela reflexão do saber fazer, elevando a prática a um nível de consciência, reflexão, análise, sistematização e intenção.

Quando Shulman utiliza a expressão Conhecimento Pedagógico do Conteúdo ao invés de saberes, está realmente igualando o status do que o professor produz na prática (PCK) aos conhecimentos que são produzidos na academia e que influenciam e são influenciados pelo PCK. Tais conhecimentos são os pertencentes à base de conhecimentos - conhecimento do tema, conhecimento pedagógico e conhecimento do contexto, estes sim informados ao professor pela academia.

Outra distinção entre a linha de investigação dos saberes dos professores e a dos conhecimentos dos professores é o papel central do conhecimento do conteúdo específico valorizado por Shulman. Diversos autores (CANDAU, 1999; SHULMAN, 2004; VAN DRIEL et al., 1998) defendem que a maior competência do professor é a sua disciplina, pois o professor é sempre professor de alguma disciplina e essa especificidade transparece principalmente no conceito de PCK. Dessa forma, a competência pedagógica está atrelada a um conteúdo específico que é transformado, levando em consideração as dificuldades dos alunos com esse conteúdo, o contexto, as estratégias instrucionais, os modos de avaliação, o currículo, os objetivos, etc.

Assim, neste trabalho traçaremos um panorama da corrente teórica de Shulman que assume que há um conhecimento que é produzido na sala de aula do professor ao transformar os conhecimentos da base em diálogo com a prática e produzindo um novo conhecimento, o PCK. Depois da proposta inicial de Shulman, vários autores ampliaram suas ideias com novas proposições na tentativa de explicar o conhecimento dos professores. Nessa direção, autores mais voltados para o ensino de ciências se debruçaram sobre o modelo original de Shulman e o ampliaram.

$\mathrm{Na}$ sequência sistematizaremos alguns modelos de conhecimentos de professores e de PCK propostos na literatura e suas vertentes específicas para o ensino de ciências. Nossa escolha de focar mais o PCK entre os distintos conhecimentos da 
base se dá pelo fato de concordarmos com o programa de pesquisa de Shulman, que coloca o PCK no centro dos conhecimentos de professores. Com o passar dos anos, a literatura passa a ressaltar ainda mais essa importância do PCK dentre os conhecimentos dos professores e passa a denominá-lo como o conhecimento profissional específico de professores; assim, justifica-se um olhar mais pormenorizado para esse conhecimento. Os trabalhos selecionados para esta análise foram baseados na literatura voltada para a temática em ensino de ciências, muito embora a base de conhecimentos e o PCK venham sendo estudados na formação de professores em geral. Os autores citados são os que propuseram os modelos mais citados na literatura e que têm produção sistemática na área de ensino de ciências em forma de artigos, livros e apresentações nos congressos importantes da área como a Conferência da ESERA - European Science Education Research Association, da NARST - National Academic Research in Sciente Teaching, congresso da Revista Enseñanza de las Ciências e simpósio do IOSTE - International Organization for Science and Technology Education.

\section{MODELOS DE CONHECIMENTOS DE PROFESSORES E O ENTENDIMENTO DE PCK NESS- ES MODELOS}

\section{Base de conhecimentos de Shulman}

Shulman (1986) chama a atenção para a importância do conhecimento do conteúdo específico dentre os conhecimentos que o professor deve possuir. Nas avaliações para seleção de professores que o grupo de Shulman analisou, os conhecimentos dos professores avaliados estavam mais relacionados com as questões pedagógicas do que de conteúdo específico. Na mesma direção, a didática mais tradicional procura um método de ensino universal capaz de ensinar qualquer coisa a qualquer aluno (CANDAU, 2010). Shulman valoriza o conhecimento do conteúdo específico, mas enfatiza que o professor precisa pedagogizar esse conteúdo específico de modo a fazer com que seus alunos consigam entendê-lo. Para tanto, o professor precisa dominar e transformar muito bem os conhecimentos da base em PCK.

Para Shulman (1986), todo professor é professor de alguma disciplina e é essa especificidade que está no centro da sua profissionalização. Segundo o autor, o professor deve ter domínio do conteúdo específico em três níveis: conhecimento do conteúdo em si, conhecimento curricular do conteúdo e conhecimento pedagógico do conteúdo. Em artigo de 1987 Shulman propõe que a base de conbecimentos para o ensino de um professor engloba sete conhecimentos, incluindo os três conhecimentos relacionados ao conteúdo específico apresentados anteriormente, a saber: Conhecimento do Conteúdo; Conhecimento do Currículo; Conhecimento Pedagógico do Conteúdo (PCK); Conhecimento Pedagógico Geral; Conhecimento dos Alunos e de suas características; Conhecimento dos Contextos; Conhecimento dos Objetivos, finalidades e valores educacionais, e de seus fundamentos filosóficos e históricos. E acrescenta que, dentre esses conhecimentos da base, o PCK se destaca como sendo o conhecimento exclusivo de professores. 


\section{PCK na visão inicial de Shulman}

A expressão Conhecimento Pedagógico de Conteúdo foi inicialmente apresentada por Shulman para denominar um tipo específico de conhecimento de professores, um conhecimento que diferencia um professor de uma dada disciplina de um especialista dessa mesma disciplina. Essa expressão foi nomeada pela primeira vez por ele numa conferência na Universidade do Texas em 1983, cujo título era: “O paradigma perdido na pesquisa sobre ensino." O paradigma perdido era o conteúdo específico e a escassa atenção que estava merecendo no caminho para ser professor. No artigo de 1987, Shulman descreve a ideia de PCK pela primeira vez dizendo: “[...] PCK é aquele amálgama especial entre conteúdo e pedagogia que pertence unicamente ao universo de professores, sua forma especial de entendimento profissional" (SHULMAN, 1987, p. 8, tradução nossa).

Para Shulman, ainda, é essa capacidade de transformação do conteúdo que distingue, por exemplo, um professor de química de um especialista em química. Os elementos chaves na concepção de Shulman para o PCK são conhecimentos de representações do conteúdo específico e das estratégias instrucionais, por um lado, e o entendimento das dificuldades de aprendizagem e as concepções dos estudantes de um conteúdo por outro. Assim, desde o momento em que Shulman cunhou o termo PCK, ele tem sido amplamente utilizado nas investigações de conhecimento de professores. E pela valorização dada ao conhecimento de conteúdo específico, o PCK acabou recebendo mais atenção de pesquisadores das didáticas específicas em contraposição às didáticas gerais. Nesse sentido, atualmente pesquisadores em ensino de ciências têm realizado enormes contribuições ao modelo (KIND, 2004; SCHNEIDER; PLASMAN, 2011; FERNANDEZ, 2014; FERNANDEZ; GOES, 2014). Aparentemente PCK representa o conhecimento que os professores possuem e que não havia sido anteriormente nomeado. Inicialmente Shulman definiu o PCK como:

\footnotetext{
[...] aquele conhecimento que vai além do conhecimento da matéria em si e chega na dimensão do conhecimento da matéria para o ensino. Eu [Shulman] ainda falo de conteúdo aqui, mas de uma forma particular de conhecimento de conteúdo que engloba os aspectos do conteúdo mais próximos de seu processo de ensino. [...] dentro da categoria de conhecimento pedagógico do conteúdo eu incluo, para os tópicos mais regularmente ensinados numa determinada área do conhecimento, as formas mais úteis de representação dessas ideias, as analogias mais poderosas, ilustrações, exemplos e demonstrações - numa palavra, os modos de representar e formular o tópico que o faz compreensível aos demais. Uma vez que não há simples formas poderosas de representação, o professor precisa ter em mãos um verdadeiro arsenal de formas alternativas de representação, algumas das quais derivam da pesquisa enquanto outras têm sua origem no saber da prática. (SHULMAN, 1986, p. 9)
}

\section{Base de conhecimentos de professores proposta por Grossman}

Grossman (1990), que foi orientada de Shulman durante o seu doutorado, sistematiza pela primeira vez os componentes da base de conhecimentos de professores e sua relação com o PCK num modelo muito citado na literatura: 
Figura 1: Modelo de conhecimento de professores.

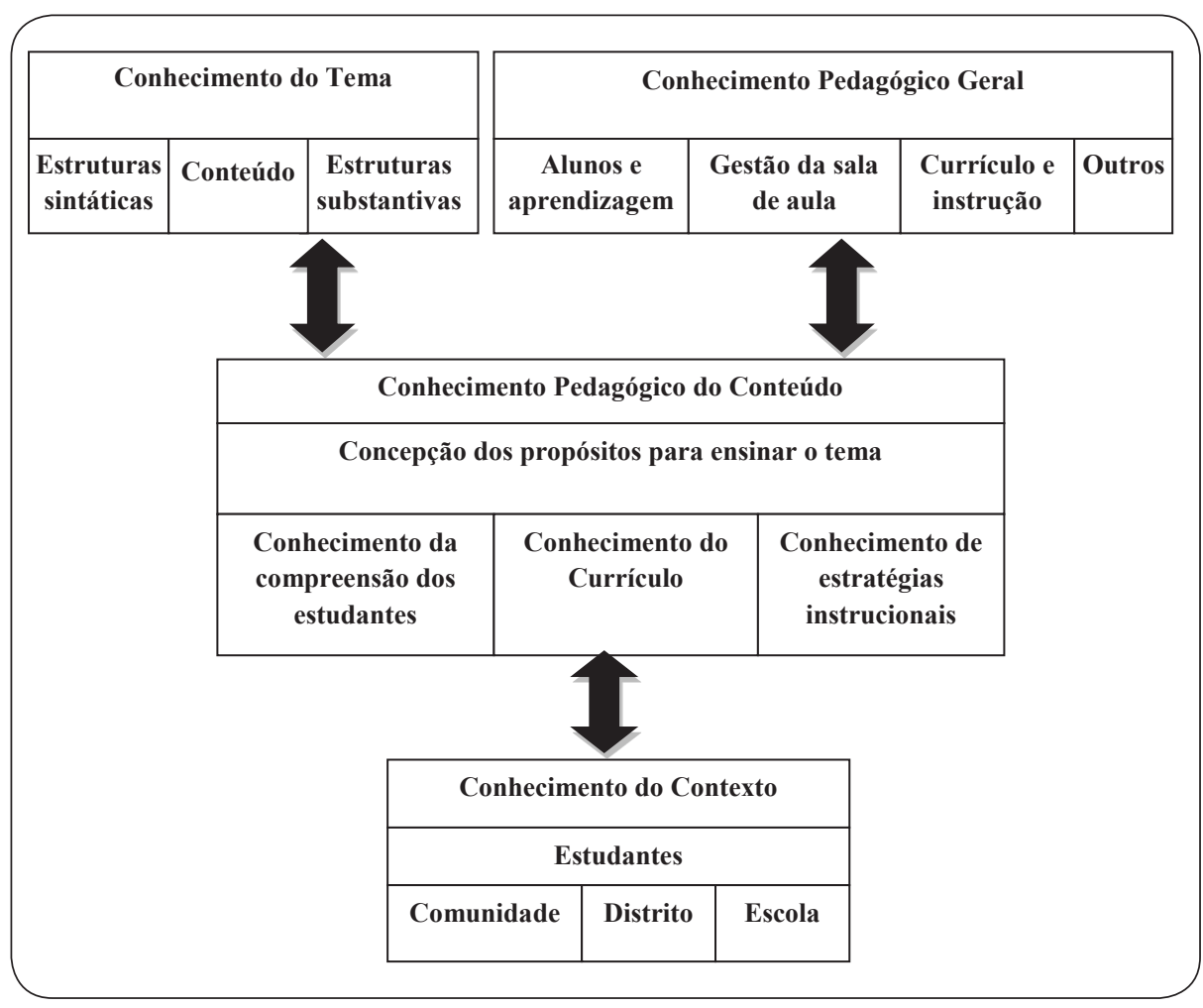

No modelo, Grossman (1990) utiliza o termo Subject Matter Knowledge traduzido por nós por Conhecimento do Tema baseado em Landau (2005) - no lugar de Content Knowledge (Conhecimento de Conteúdo), conforme Shulman utilizou na base de conhecimentos. O termo Conhecimento do Tema traduz melhor o entendimento do próprio Shulman, pois engloba não somente o conhecimento do conteúdo específico como o conhecimento das estruturas sintáticas e substantivas do conteúdo (SCHWAB, 1964). Assim, a compreensão do professor requer ir além dos fatos e conceitos intrínsecos da disciplina e pressupõe o conhecimento das formas pelas quais os princípios fundamentais de uma área do conhecimento estão organizados, a compreensão dos processos de sua produção, representação e validação epistemológica. Espera-se que o professor possua a compreensão do porquê de um determinado tópico ser particularmente central para uma disciplina enquanto outros podem ser periféricos.

\section{PCK segundo Grossman}

No modelo de conhecimento de professores de Grossman (Figura 1) fica explícito seu entendimento sobre o PCK. Para a autora, o PCK é o conhecimento 
central dentre os conhecimentos da base que influencia e é influenciado por eles e é constituído do conhecimento da compreensão dos estudantes; do conhecimento do currículo e do conhecimento das estratégias instrucionais. Ainda, todos esses conhecimentos que constituem o PCK estão subordinados às concepções dos propósitos para ensinar um tema. Dessa forma, fica explicitado o caráter formal e prático do PCK uma vez que conhecimentos e crenças dos professores estão presentes no modelo (Figura 1). Esse entendimento dos componentes do PCK em Grossman dialoga com a concepção inicial de Shulman somando o conhecimento do currículo e as concepções dos propósitos para ensinar um tema.

\section{Modelo da base de conhecimentos de professores de Carlsen e o destaque do contexto}

O modelo de Carlsen (1999) se assemelha ao de Grossman exceto no destaque feito ao contexto geral e específico não como um conhecimento em si, mas como um pano de fundo dos demais conhecimentos (Figura 2).

O conhecimento sobre contexto educacional geral inclui a nação, o Estado, a comunidade e as escolas, enquanto o conhecimento sobre o contexto educacional específico foca na sala de aula e nos alunos. Outra diferença significativa em relação ao modelo de Grossman (1990), Figura 1, é o fato de os propósitos para o ensino de ciências estarem no mesmo nível hierárquico dos demais componentes do PCK no modelo de Carlsen. Esse modelo é pensado exclusivamente para o ensino de ciências.

Figura 2. Domínios dos conhecimentos de professores de ciências

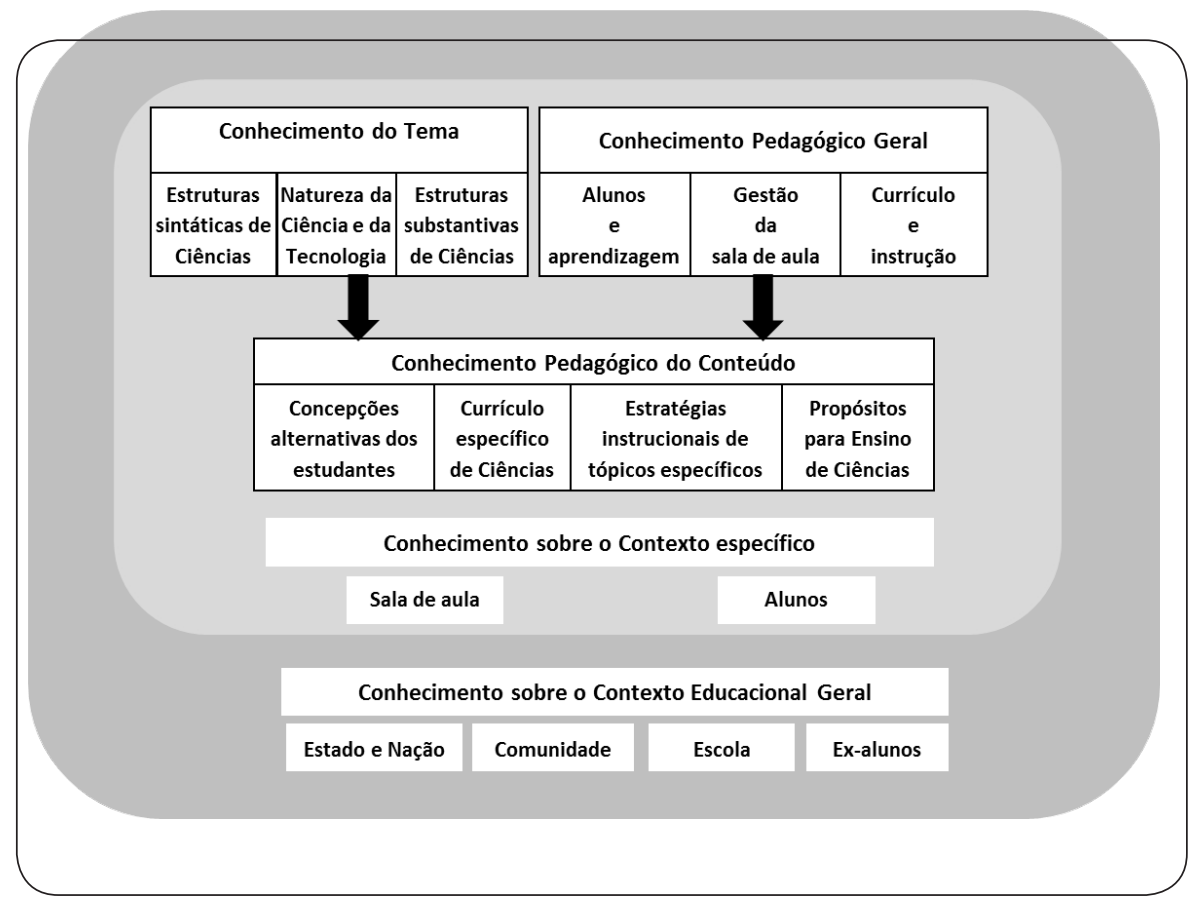

Fonte: CARLSEN, 1999, p.136, tradução nossa. 


\section{Modelo de PCK segundo Carlsen}

No modelo de Carlsen (Figura 2), o PCK é entendido da mesma forma que em Grossman (Figura 1) com a única ressalva de que os propósitos para o ensino de ciências terem sido colocados no mesmo nível hierárquico dos demais componentes.

No nosso ponto de vista, a visão de Grossman traduz melhor o PCK dos professores, pois as concepções dos propósitos para o ensino de um dado tema são anteriores e influenciam tanto o conhecimento da compreensão dos estudantes, currículo e estratégias instrucionais, como direciona de que forma esses conhecimentos serão utilizados na prática. $\mathrm{Na}$ visão de Carlsen, ao colocar no mesmo nível os propósitos para o ensino e os demais componentes do PCK, não se enfatiza a relação de causa e consequência que o modelo de Grossman expressa. Concordamos com Grossman que as concepções dos propósitos do ensino de um tema podem alterar toda a importância dos demais componentes e seu consequente uso em sala de aula, além de enfatizar o caráter formal e prático do PCK uma vez que conhecimentos e crenças dos professores acabam convivendo na prática e são considerados no modelo.

No nosso ponto de vista, esse modelo não acrescenta muito em relação ao modelo de Grossman, uma vez que este já considerava o conhecimento do contexto como algo que influencia e é influenciado pelo PCK. O fato de o contexto estar enfatizado "embebendo" todos os demais conhecimentos no modelo de Carlsen parece mais uma variante do que uma nova proposta. Além disso, parecem mais razoáveis os propósitos para ensinar um tema possuírem uma hierarquia em relação aos demais conhecimentos que compõem o PCK, como apontado no modelo de Grossman.

\section{Modelo de Morine-Dershimer e Kent e o destaque do conhecimento pedagógico}

Morine-Dershimer e Kent (1999) apresentam um modelo em que mostram sua interpretação do lugar do conhecimento pedagógico em relação ao conjunto de categorias de conhecimento de professores identificadas por Shulman (1987) e as categorias que contribuem para o PCK (Figuras 3a e 3b).

Em relação ao conhecimento pedagógico ressaltam três pontos. Um deles é a estreita relação apresentada no modelo entre o conhecimento das finalidades e propósitos e sua inseparabilidade do conhecimento sobre processos de avaliação. Outro é que o conhecimento do currículo é alimentado tanto pelo conhecimento do conteúdo como pelo conhecimento dos objetivos/processos de avaliação. E ainda no modelo, cada uma das demais categorias está diretamente vinculada ao conhecimento pedagógico do conteúdo, isto é, conhecimento do conteúdo específico, do currículo específico, dos objetivos/processos de avaliação, da pedagogia específica e dos estudantes (MORINE-DERSHIMER; KENT, 1999).

Para esses autores, portanto, o PCK é influenciado pelos seis conhecimentos da base: i) conhecimento dos propósitos e dos objetivos educacionais / conhecimentos dos processos de avaliação; ii) conhecimento pedagógico; iii) conhecimento do currículo; iv) conhecimento do conteúdo; v) conhecimento dos contextos específicos; e vi) conhecimento dos aprendizes e aprendizagem. 
Figura 3. A-Facetas do Conhecimento Pedagógico e B-Categorias que contribuem para o PCK
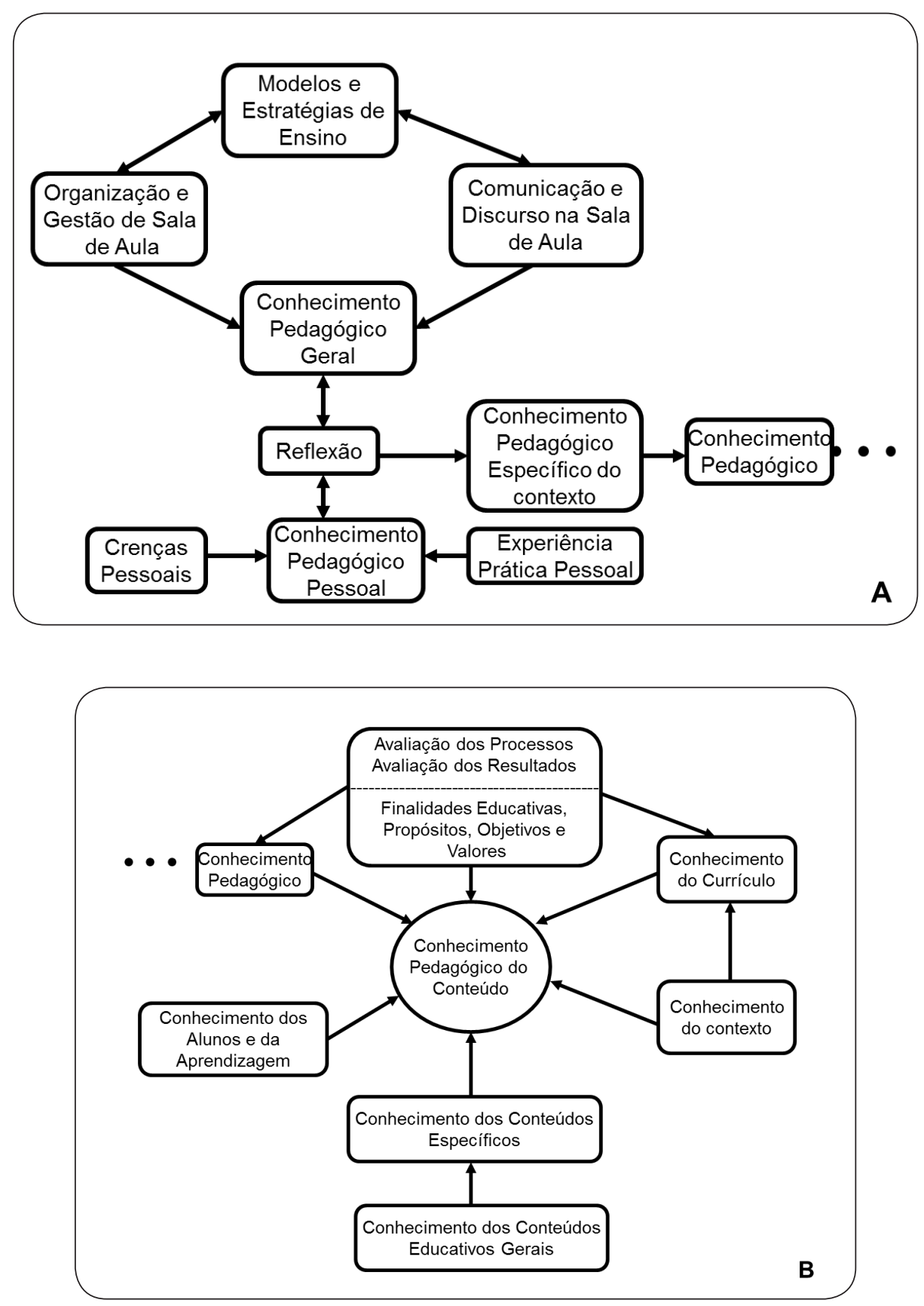

Fonte: MORINE-DERSHIMER; KENT, 1999, p. 22, tradução nossa. 
Cabe salientar aqui a relação entre conhecimento pedagógico geral, que é fruto da pesquisa e literatura educacional e o conhecimento pedagógico pessoal que é abastecido das crenças pessoais construídas a partir das experiências vividas e experiência prática pessoal. O processo de reflexão promove a conexão entre o conhecimento pedagógico geral e o pessoal de forma que as percepções formadas pelas crenças pessoais e experiências são ampliadas e tornadas mais objetivas, enquanto concepções e princípios da pedagogia explicados pela pesquisa são exemplificados e contextualizados. O resultado desse processo é um conhecimento pedagógico específico do contexto que ajuda a guiar as decisões e ações dos professores (MORINE-DERSHIMER; KENT, 1999).

Nesse modelo, aparece uma preocupação com a avaliação e sua estreita relação com os propósitos iniciais do ensino. Além disso, no modelo são explicitadas as crenças pessoais e sua relação com o PCK através do conhecimento pedagógico, das experiências pessoais e da reflexão, componentes ausentes nos modelos anteriores.

\section{Modelo de Domínios de Conhecimentos de professores de Química e suas mani- festações - Rollnick}

Nesse modelo há uma diferenciação entre o que são os conhecimentos do professor, algo que não é palpável, e quais as manifestações desses conhecimentos em sala de aula, essas sim, observáveis na prática didática. Nas observações em sala de aula, com professores de Química da África do Sul numa pesquisa cujo objetivo era analisar o peso do conhecimento do conteúdo dentro do conhecimento pedagógico do conteúdo, os autores concluíram que as manifestações desses domínios geram o que eles denominaram de "produtos do ensino" (Figura 4). As manifestações são: a) Representações do conteúdo; b) Estratégias instrucionais de um conteúdo específico; c) Saliência curricular; d) Avaliação. (ROLLNICK et al., 2008). Esses autores consideram que o PCK sofre influências de quatro domínios do conhecimento base para o ensino: a) Conhecimento do conteúdo; b) Conhecimento dos estudantes; c) Conhecimento pedagógico geral e; d) Conhecimento do contexto.

Esse modelo, além de separar conhecimentos de manifestações, resgata a ideia original de Shulman para o PCK enfocando nas representações de conteúdo e nas estratégias instrucionais de um tópico e introduz a questão da avaliação como uma manifestação dos conhecimentos dos professores. Também coloca a saliência curricular como uma manifestação do conhecimento do professor, o que faz todo sentido, pois, se o professor conhece o currículo que ensina, pode fazer seleções e alterações mais condizentes com seu público e contextos. 
Figura 4. Modelo adaptado para o PCK

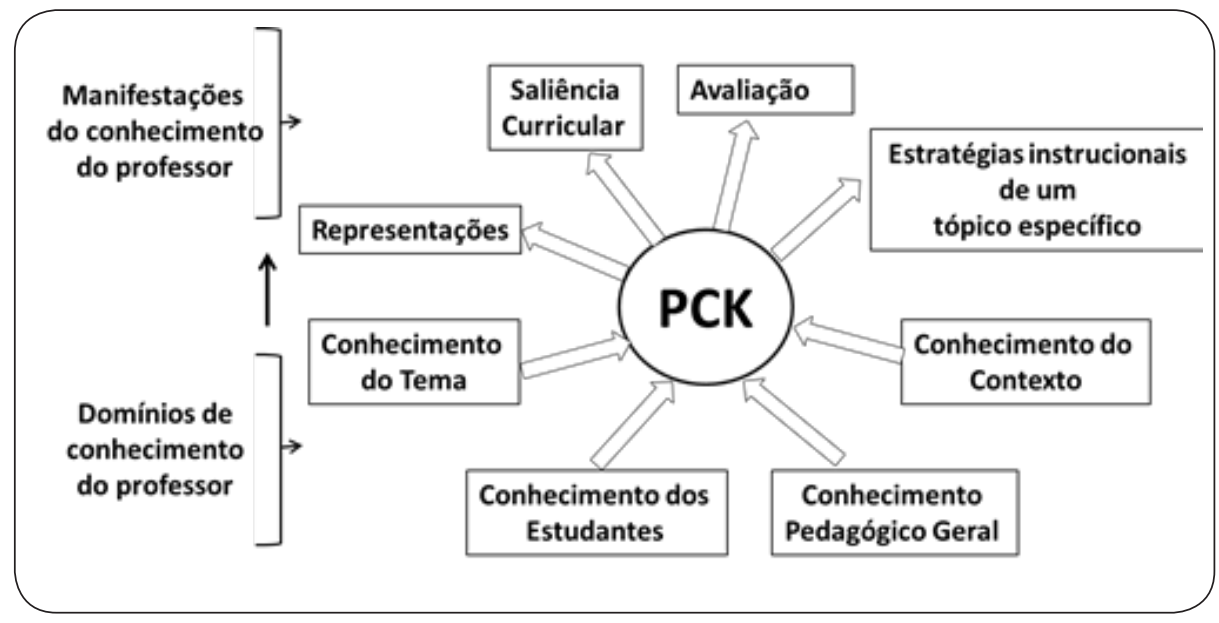

Fonte: ROLLNICK et al., 2008, p. 1381, tradução nossa.

\section{Modelo de PCK de Magnusson, Krajcik e Borko}

A partir do modelo dos conhecimentos base de professores de Grossman, muitas propostas surgiram para representar o PCK, especialmente vindas de pesquisadores da área de ensino de ciências. Entre elas, destacamos o modelo de Magnusson, Krajcik e Borko (1999), que enfatiza os componentes do PCK para o ensino de ciências (Figura 5).

Esse modelo segue basicamente a proposta de PCK de Grossman, acrescentando o conhecimento da avaliação como um dos componentes do PCK. Além disso, nesse modelo, as "concepções dos propósitos para ensino de um conteúdo” presente em Grossman são substituídas pelas “orientações para o ensino de ciências". Tais orientações são explicitadas pelos autores em: processo, rigor acadêmico, didática, mudança conceitual, atividade dirigida, descoberta, ciência baseada em projetos, ensino por investigação, investigação orientada, todas voltadas para o ensino de ciências.

Apesar das contribuições e da popularidade do modelo de Magnusson, Krajcik e Borko, (1999), algumas críticas têm sido feitas, e a principal vem de Friedrichsen, Van Driel e Abell (2010), que apontam restrições para o uso do termo "orientações para o ensino de ciências". Segundo os autores esse termo é utilizado com significados diferentes reportados na literatura e essa ambiguidade seria resultado da própria origem do termo, que é definido, num primeiro momento, como sendo os "conhecimentos e crenças sobre os propósitos e objetivos do ensino de ciências em um determinado nível de ensino", considerando o professor como participante do processo, e, em um segundo momento, como sendo "uma visão geral de entendimento do ensino de ciências." Esse modelo é, entretanto, um dos mais utilizados e parece congregar 
o pensamento de mais pesquisadores da área de ensino de ciências e tem sido ampliado e/ou ligeiramente modificado.

Figura 5. Componentes do Conhecimento Pedagógico do Conteúdo para o Ensino de Ciências

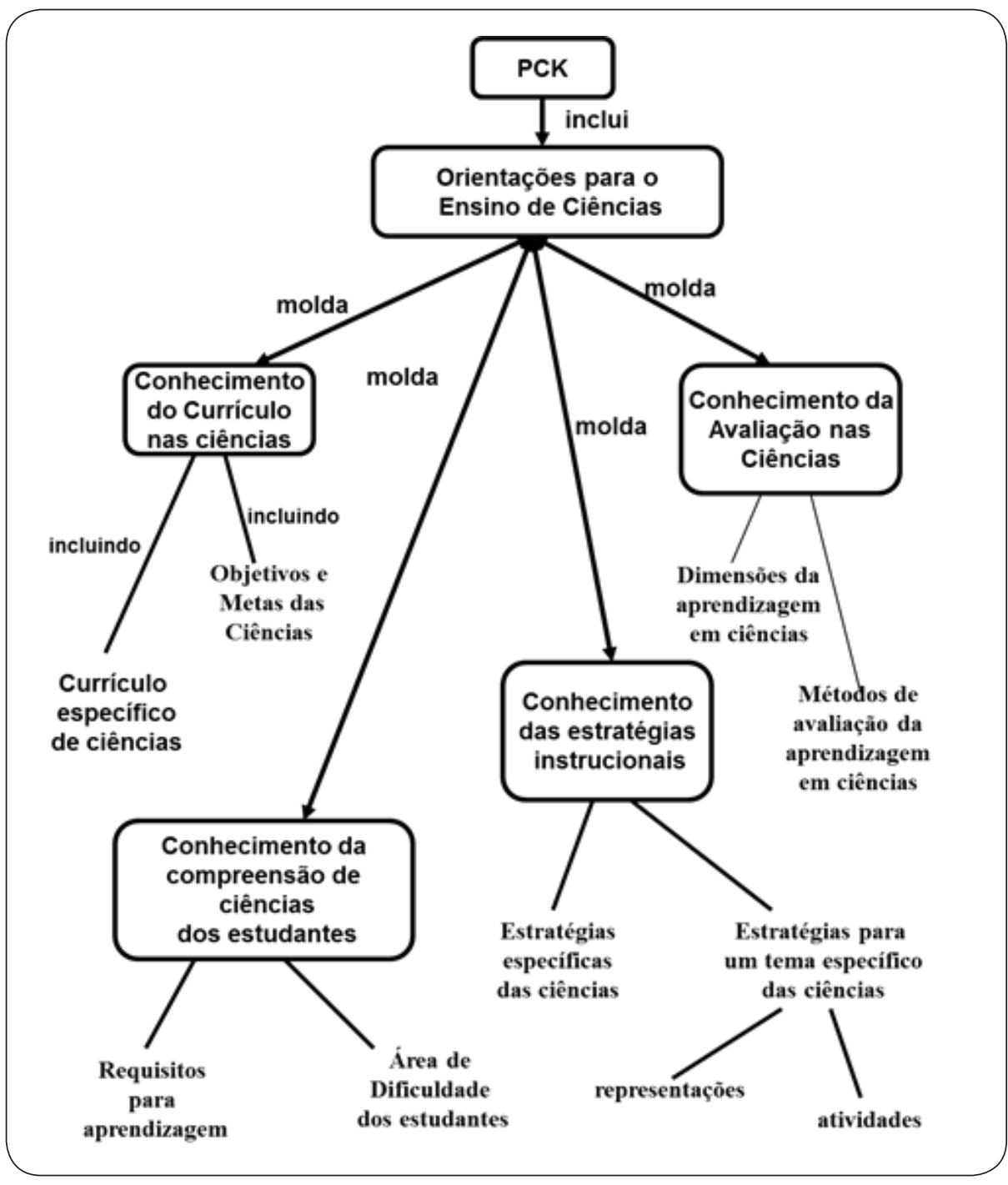

Fonte: MAGNUSSON; KRAJCIK; BORKO, 1999, p. 99, tradução nossa.

\section{Modelo de PCK Park e Oliver}

No trabalho de Park e Oliver (2008), foi adicionado um sexto componente ao modelo de Magnusson, Krajcik e Borko referente à eficácia do professor. A perspectiva afetiva tem tido destaque na literatura como sendo um dos componentes do PCK. Os autores denominaram esse modelo de He- 
xagonal e também é específico para o ensino de ciências (Figura 6).

Figura 6. Modelo Hexagonal do conhecimento pedagógico do conteúdo para o ensino de Ciências

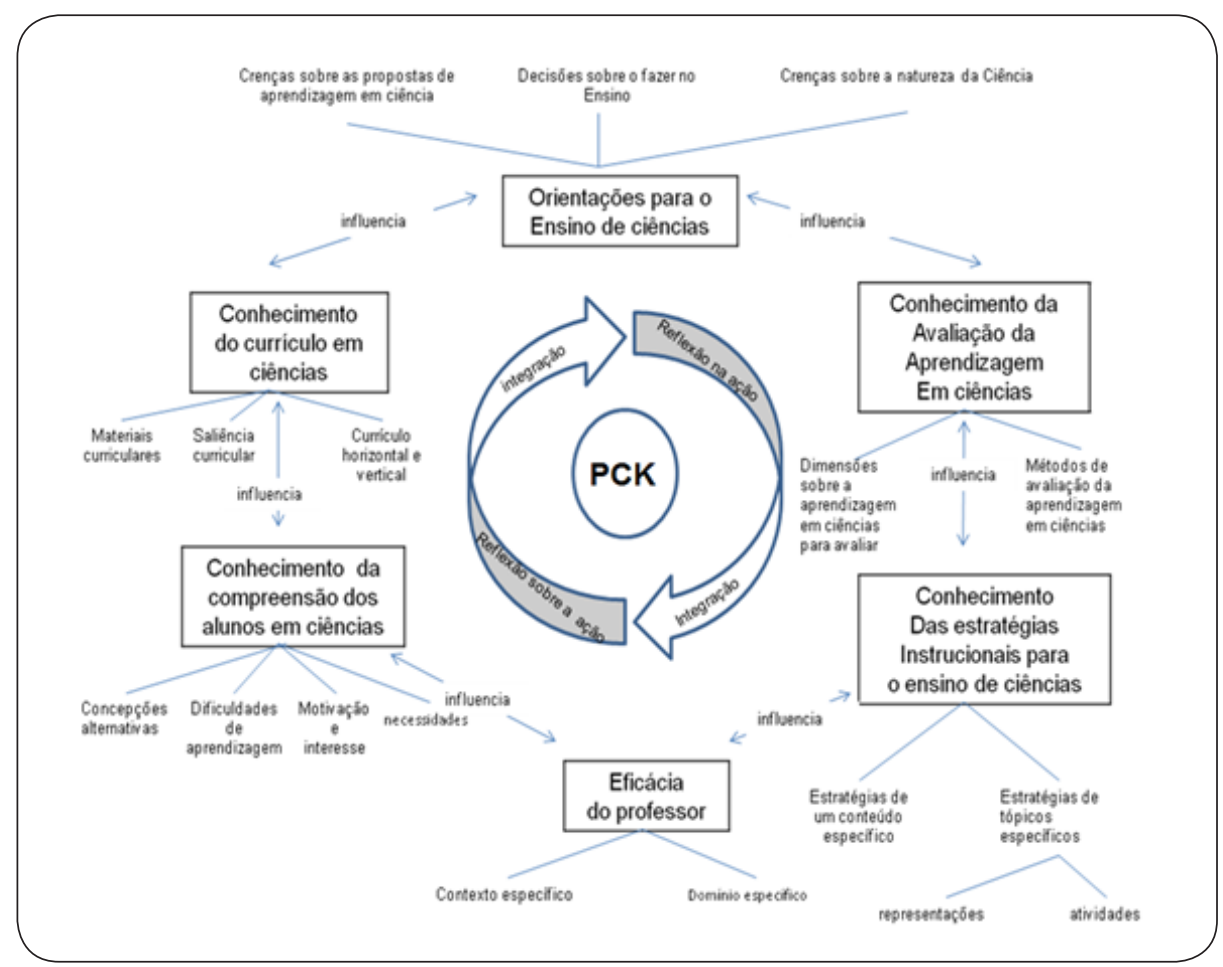

Fonte: PARK; OLIVER, 2008, p. 279, tradução nossa.

Nesse modelo, as orientações para o ensino de Ciências influenciam não somente o PCK, como no modelo de Grossman, mas também influenciam os conhecimentos da base. Além disso, o componente eficácia que aparece nesse modelo direciona o professor para ações que ele percebe serem mais eficazes na sala de aula. Nesse modelo também há uma abertura para o entendimento de como o PCK se desenvolveria na prática de professores - através de processos de reflexão na ação e sobre a ação, resgatando a ideia do modelo de raciocínio pedagógico e ação de Shulman, apresentado mais adiante na figura 9.

\section{Modelo de Abell - base de conhecimentos de Grossman e PCK de Magnusson, Krajcik e Borko}

Abell sugere um modelo de conhecimento de professores de ciências que engloba os dois modelos mais utilizados na literatura: os modelos de Grossman (1990, Figura 1) da base de conhecimento de professores e dos componentes do PCK de Magnusson, Krajcik e Borko (1999) (Figura 5) apre- 
sentando, assim, um modelo que se mostra bastante útil para o ensino de ciências. (Figura 7).

Figura 7. Modelo de conhecimento de professores de ciências (Modificado de Grossman, 1990 e Magnusson, Krajcik e Borko, 1999)

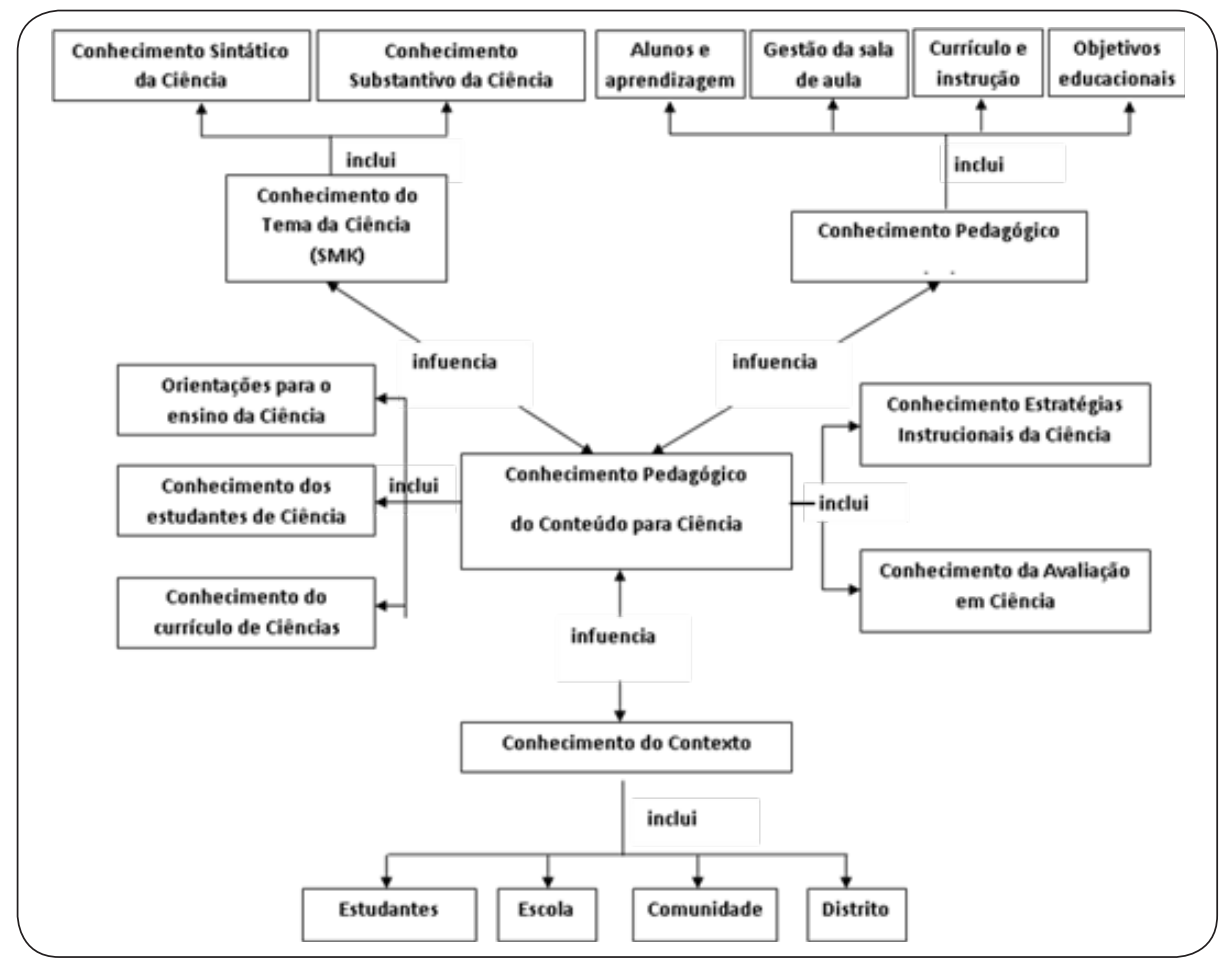

Fonte: ABELL, 2008, p. 1.107, tradução nossa.

\section{Modelo da Cúpula do PCK}

Este é o modelo mais recente e é resultado de uma conferência realizada em 2012, na qual trinta grupos de pesquisadores em Ensino de Ciências (englobando grupos de pesquisa em Ensino de Física, Química e Biologia) que trabalham com PCK se reuniram e discutiram sobre esse constructo com intuito de chegarem a um consenso sobre a definição da base de conhecimentos e o PCK a partir das concepções adotadas pelos distintos grupos (Figura 8).

No modelo da cúpula são definidos cinco conhecimentos base: i) conhecimento da avaliação; ii) conhecimento pedagógico; iii) conhecimento do conteúdo; iv) conhecimento dos alunos e v) conhecimento curricular. Esses cinco conhecimentos influenciam e são influenciados pelo conhecimento profissional de um determinado tópico, sendo esse conhecimento profissional (PCK) representado pelo conhecimento das estratégias instrucionais, das representações do conteúdo, da compreensão dos alunos, das práticas científicas e dos modos de pensar. 
Figura 8. Modelo consensual de PCK no ensino de ciências da cúpula do PCK

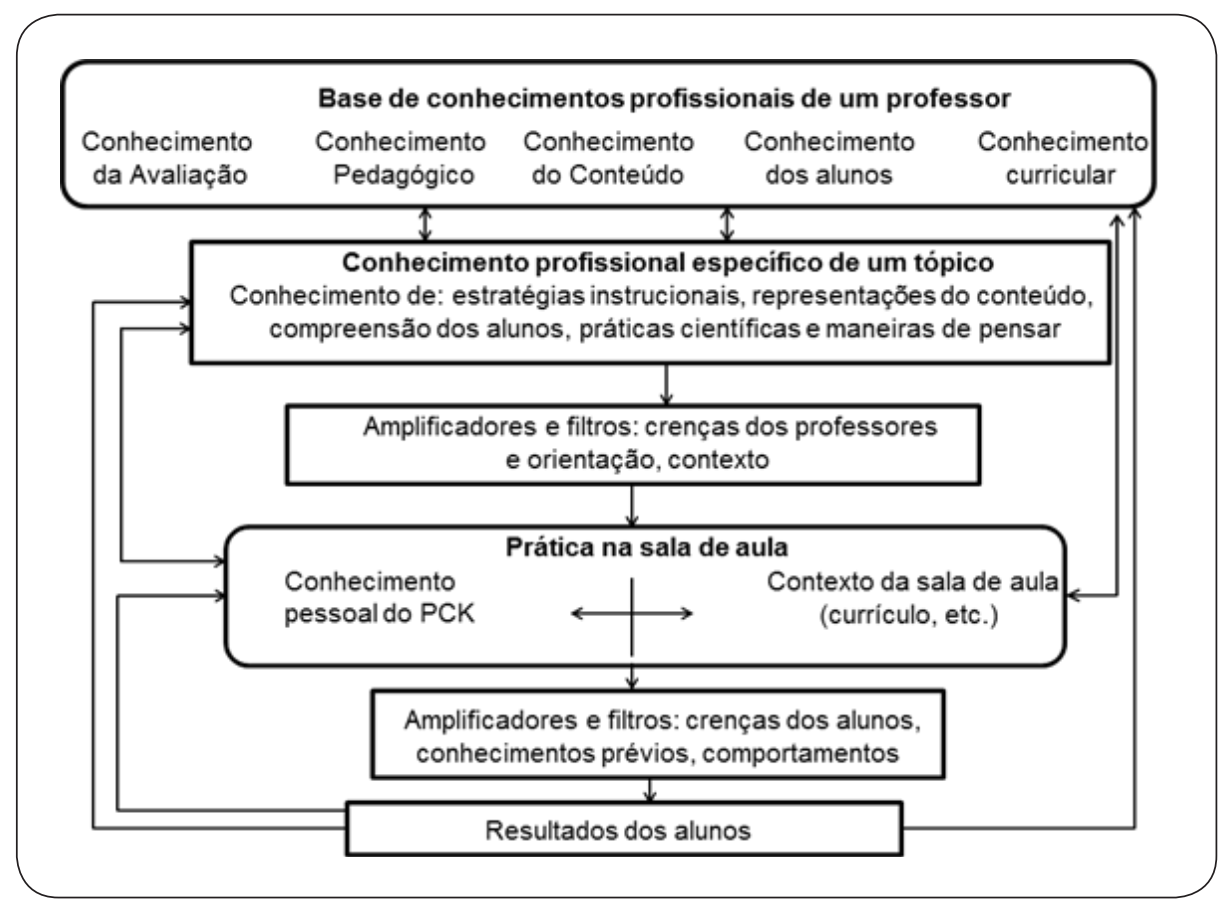

Fonte: HELMES; STOKES, 2013; GESS-NEWSOME; CARLSON, 2013, tradução nossa.

No modelo, o conhecimento profissional específico (PCK) passa por filtros e amplificadores, que são as crenças dos professores, o contexto no qual ele está inserido e as orientações para o ensino, e, depois desse filtro, esse conhecimento profissional específico será transformado e adaptado para a sala de aula sofrendo influência do conhecimento pessoal do PCK, do contexto de sala de aula, do currículo etc.. Na sequência há os filtros e amplificadores dos alunos, levando em consideração suas próprias crenças, conhecimentos prévios e seus comportamentos, que irão direcionar os resultados dos alunos.

Por outro lado, os resultados dos alunos realimentam os conhecimentos profissionais da base e o conhecimento profissional específico de um tópico. Da mesma forma, os resultados dos alunos realimentam também a prática da sala de aula e esta fornece uma nova compreensão ao PCK de um tópico.

Observa-se que nesse modelo há um PCK mais formalizado (conhecimento profissional específico do tópico) e um conhecimento pessoal do PCK, idiossincrático, que se manifesta na prática da sala de aula, sendo que essa prática influencia e é influenciada tanto pelos conhecimentos da base como pelo conhecimento profissional específico do tópico. Os resultados dos alunos, por sua vez, influenciam tanto o PCK pessoal da prática em sala de aula, quanto o conhecimento profissional específico do tópico, assim como os conhecimentos da base. É através 
dessa relação, em que a prática de sala de aula é influenciada e influencia os demais conhecimentos, que se observa que o modelo pressupõe construção com base na ação, ou seja, o professor é um agente reflexivo que reflete sobre sua prática e a reavalia com o objetivo de alcançar resultados melhores com seus alunos reconstruindo e transformando seu conhecimento pessoal de PCK, seu conhecimento profissional específico de um tópico e seus conhecimentos da base. Esse modelo revela não só os conhecimentos que estão sendo mobilizados, mas também como ocorre o desenvolvimento do PCK dos professores e dialoga nesse sentido com o Modelo de Raciocínio Pedagógico e Ação proposto por Shulman que será apresentado mais adiante, na Figura 9.

\section{Acesso, documentação e análise do PCK de professores de ciências}

O estudo do PCK de um professor é bastante complexo, devido, entre outros aspectos, ao fato de se tratar de um conjunto de conhecimentos implícitos, que devem ser de alguma forma explicitados. Assim, diversas maneiras foram propostas e avaliadas para que se procurasse documentar e investigar o PCK de um professor. (FERNANDEZ; GOES, 2014).

Baxter e Lederman (1999) compilaram as fontes de dados mais utilizadas: avaliações e testes, observação da sala de aula, mapas conceituais, representações pictóricas, entrevistas e avaliação por métodos múltiplos. Em sua revisão Kind (2009) separa os métodos de acesso ao PCK em dois grupos: estudos in situ e estudos testes. Estudos in situ investigam como os professores ensinam ciência dentro da sala de aula. Os estudos testes, por sua vez, investigam a percepção do professor sobre o PCK e se há alguma mudança durante ou depois da intervenção. Nesse caso, os professores investigados são expostos a trechos de vídeos ou transcrições de aulas e depois são utilizados um ou mais instrumentos de coleta de dados para acessar o PCK.

Dois instrumentos específicos têm sido bastante utilizados no ensino de ciências, o CoRe (Representação do Conteúdo) (LOUGHRAN; BERRY; MULHALL, 2004) e o PaP-eR (Repertório de experiência Pedagógica e Profissional) (LOUGHRAN et al., 2001).O CoRe busca acessar o conhecimento do professor sobre o ensino de determinado conteúdo e permite analisar aspectos particulares do PCK. É considerado tanto um instrumento de pesquisa como uma alternativa para estimular o desenvolvimento profissional. Consiste de oito questões sobre o ensino de um conteúdo específico, podendo ser usado individualmente ou em grupo (Quadro 1). Por outro lado, o PaP-eR emerge de situações reais da prática docente e não se aplica, necessariamente, a um professor particular. Trata-se de uma narrativa da prática baseada em registros de aulas e na reflexão do professor e é elaborado pelo pesquisador a partir de descrições detalhadas sobre o ensino de um conteúdo, extraídas de entrevistas, de ideias manifestadas em discussões e interações durante a prática de ensino, entre outras. (LOUGHRAN; BERRY; MULHALL, 2006). A maioria dos trabalhos utiliza métodos múltiplos para gerar dados com maior confiabilidade. Há vários exemplos de trabalhos em ensino de 
ciências/química em que esses instrumentos foram utilizados e os dados triangulados (FERNANDEZ, 2011, 2014a, 2014b; FREIRE; FERNANDEZ, 2014, 2015; GARRITZ; TRINIDAD-VELASCO, 2004; GIROTTO-JR; FERNANDEZ, 2013; GOES, 2014; GOES et al., 2013; MONTENEGRO; FERNANDEZ, 2015; NOVAIS; FERNANDEZ, 2013; 2014; OLIVEIRA JÚNIOR, 2012; PEREIRA; FERNANDEZ, 2013; SALES, 2010; SILVA, 2012).

Quadro 1. Instrumento CoRe - Representaç̃̃es do Conteúdo

\begin{tabular}{|c|c|c|c|c|}
\hline & & \multicolumn{3}{|c|}{ Conteúdo específico } \\
\hline & & \multicolumn{3}{|c|}{ Ideias Centrais } \\
\hline Lista de funções criadas a partir das paráfrases & Ideia 1 & Ideia 2 & Ideia 3 & Etc. \\
\hline \multicolumn{5}{|l|}{$\begin{array}{l}\text { 1. } 0 \text { que você pretende que os alunos aprendam } \\
\text { sobre essa ideia? }\end{array}$} \\
\hline \multicolumn{5}{|l|}{$\begin{array}{l}\text { 2. Por que é importante para os alunos } \\
\text { aprenderem essa ideia? }\end{array}$} \\
\hline \multicolumn{5}{|l|}{ 3. 0 que mais você sabe sobre essa ideia? } \\
\hline \multicolumn{5}{|l|}{$\begin{array}{l}\text { 4. Quais são as dificuldades e limitações ligadas } \\
\text { ao ensino dessa ideia? }\end{array}$} \\
\hline \multicolumn{5}{|l|}{$\begin{array}{c}\text { 5. Que conhecimento sobre o pensamento dos } \\
\text { alunos tem influência no seu ensino sobre essa } \\
\text { ideia? }\end{array}$} \\
\hline \multicolumn{5}{|l|}{$\begin{array}{l}\text { 6. Que outros fatores influem no ensino dessa } \\
\text { ideia? }\end{array}$} \\
\hline \multicolumn{5}{|l|}{$\begin{array}{l}\text { 7. Que procedimentos/ estratégias você emprega } \\
\text { para que os alunos se comprometam com essa } \\
\text { ideia? }\end{array}$} \\
\hline $\begin{array}{c}\text { 8. Que maneiras específicas você utiliza para } \\
\text { avaliar a compreensão ou a confusão dos alunos } \\
\text { sobre essa ideia? }\end{array}$ & & & & \\
\hline
\end{tabular}

Fonte: LOUGHRAN; BERRY; MULHALL, 2004, tradução nossa.

\section{Desenvolvimento do PCK e o currículo de formação de professores de ciências}

No artigo de 1987, Shulman apresenta a proposta de um Modelo de Raciocínio Pedagógico e Ação (MPRA) que representa o processo de desenvolvimento profissional de um professor, ou seja, o processo pelo qual o professor desenvolve o seu PCK (Figura 9). Shulman explica que a maior parte dos processos de ensino se inicia por alguma forma de "texto", um livro didático, um roteiro ou outro tipo de material que o professor ou os estudantes gostariam de compreender. Segundo o MRPA, dado um texto didático, objetivos educacionais, e um conjunto de ideias, o raciocínio pedagógico e a ação envolvem um ciclo através de atividades de compreensão, transformação, instrução, avaliação, reflexão e nova compreensão. O ponto de partida e término do processo são atos de 
compreensão. Devido à sua natureza processual, o MRPA requer processos de raciocínio do professor sobre o conteúdo para o ensino que estão em reestruturação contínua. Sua dinâmica vai sendo enriquecida pelo contexto em que se sucede, como resultado das interações sociais que a atividade educativa implica e os momentos distintos que caracterizam a prática docente. O MRPA é, assim, um modelo dinâmico e cíclico de reflexão e ação docente. Em cada etapa, uma série de conhecimentos e habilidades é necessária. Sendo assim, no modelo de MRPA, Shulman representa as etapas que ocorrem para o desenvolvimento da prática profissional de um professor, sempre frente a um determinado tópico.

Figura 9. Modelo de Raciocínio Pedagógico e Ação (MRPA) proposto por Shulman (1987) e adaptado por Salazar (2005) - tradução nossa

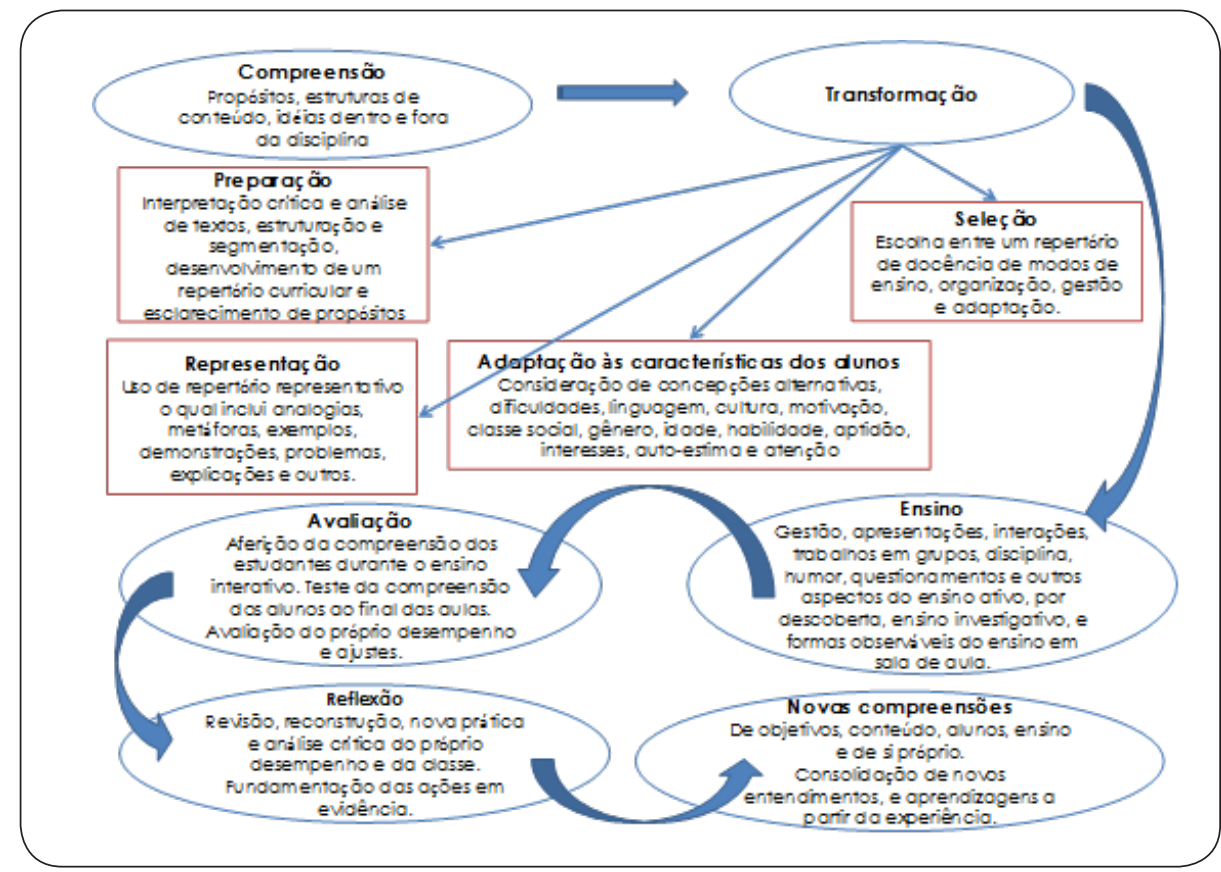

Fonte: SALAZAR, 2005

Numa tentativa de compilar dados da literatura, Gess-Newsome (1999) propõe dois modelos teóricos para tentar explicar a formação e o desenvolvimento do PCK: o Modelo Integrativo e o Modelo Transformativo (figura 10). O Modelo Integrativo considera o PCK como a intersecção entre os conhecimentos pedagógico, disciplinar e de contexto. O Modelo Transformativo coloca o PCK como resultado de uma transformação do conhecimento pedagógico, do conteúdo e do contexto.

Os dois modelos representam os extremos de um contínuo. No Modelo Integrativo, o PCK não existe como um domínio de conhecimento e o conhecimento de professores seria explicado simplesmente pela integração de três 
construtos - o conteúdo, a pedagogia e o contexto. Ensinar, segundo essa visão, seria o ato de integrar esses três conhecimentos (figura 10). No outro extremo, o PCK seria a síntese de todos os conhecimentos necessários para a formação de um professor. Nesse caso, o PCK seria a transformação do conhecimento do conteúdo, da pedagogia e do contexto até uma forma distinta - a única forma de conhecimento que traria impacto na prática dos professores, o PCK (Modelo Transformativo, figura 10). No Modelo Integrativo os conhecimentos podem desenvolver-se em separado para depois se integrarem na ação docente enquanto no Modelo Transformativo esses conhecimentos se transformam em PCK durante a prática docente, como conhecimento base para o ensino. Dados empíricos com professores de ciências revelam que os dois modelos podem ocorrer, dependendo do momento profissional do professor (KIND, 2009). Esses modelos trazem implicações para o currículo de formação de professores de ciências. Os cursos de formação de professores mais tradicionais, organizados em disciplinas separadas de conteúdo, pedagogia e prática seguem frequentemente o modelo integrativo de conhecimento de professores. Já para o modelo transformativo, a prática da sala de aula tem de fazer parte da formação inicial, assim como estudos de caso e vinhetas, entre outras atividades práticas. (GESS-NEWSOME, 1999; KIND, 2009).

Figura 10. Modelos de desenvolvimento Integrativo e Transformativo do PCK.

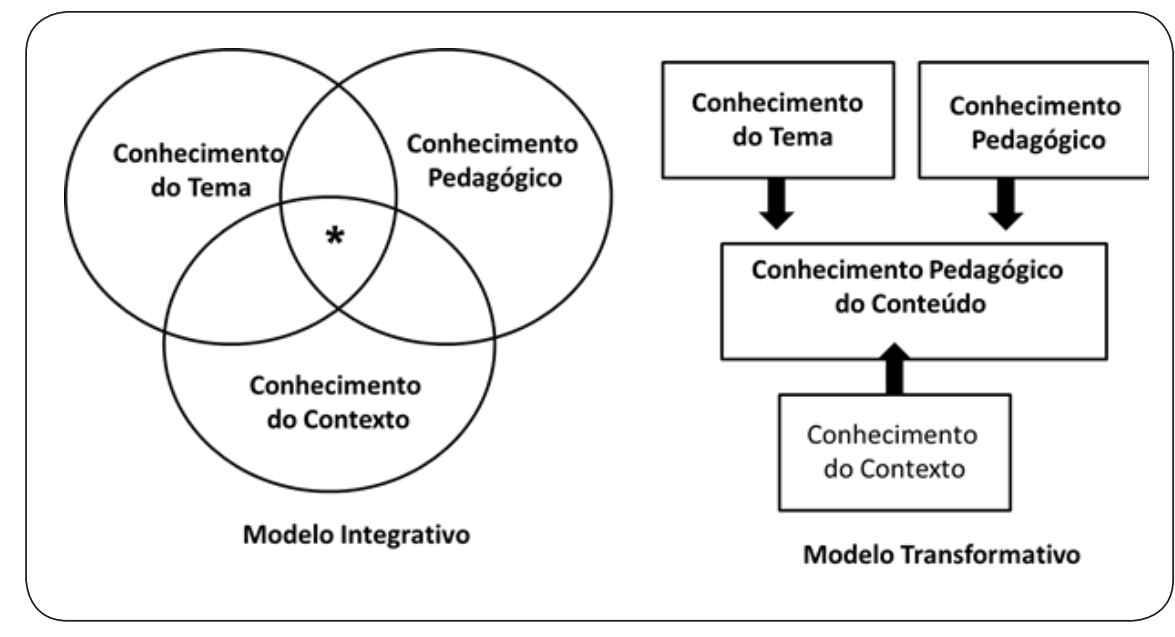

* = conhecimento necessário para o ensino na sala de aula.

Fonte: GESS-NEWSOME, 1999, p. 12, tradução nossa.

Portanto, mais dados empíricos são necessários em distintos níveis para se entender como ocorre o desenvolvimento do PCK e embasar as políticas públicas de formação de professores de ciências.

Abell $(2007,2008)$ acredita que os formadores dos professores de ciências 
deveriam dar atenção explícita para os componentes do PCK individualmente como uma forma de auxílio à aprendizagem para os professores novatos. Barnett e Hodson (2001) defendem que os professores experientes têm um conhecimento mais acessível, útil e organizado do que os professores novatos. Para ele, os novatos "acessam" o conhecimento dos conceitos, procedimentos e estratégias um por um, enquanto os professores experientes utilizam os conhecimentos mais relevantes de forma integrada. Assim, trabalhar com discussão em grupo, na qual membros mais e menos experientes discutam sobre suas próprias crenças pessoais e suas práticas e sobre as crenças pessoais e práticas dos outros membros permitiria que cada um compreendesse as características distintas dos contextos em que atuam. Nilsson (2008) salienta que a reflexão pelo licenciando em ciências do seu desenvolvimento profissional torna-o consciente da sua própria aprendizagem. De Jong, Veal e Van Driel (2002), referindo-se aos elementos formativos que ajudariam a construir o PCK dos licenciandos em ciências, reafirmam a importância da incorporação da prática docente ao processo de formação, juntamente com a discussão de textos sobre o trabalho educativo, como as concepções alternativas dos estudantes e como eles raciocinam. Rollnick et al. (2008) defendem que o PCK deve ser inserido na formação dos professores de ciências, pois, isso poderia ajudar professores inexperientes em sua formação.

Para Talanquer (2004) a diferença entre o professor de ciências experiente e o professor recém-formado está, por exemplo, no fato de que, ao escolher uma atividade, o professor novato seleciona um livro e segue a sequência proposta pelo autor. Já o professor experiente "olha" para o livro de forma completamente distinta:

[...] a tarefa demanda que o docente reflita sobre as metas, propósitos e a filosofia do que fazer em química em um dado contexto de nível de desenvolvimento intelectual, conhecimento prévio, interesse e motivações dos seus estudantes. (TALANQUER, 2004, p. 62, tradução nossa)

Ainda segundo Talanquer (2004), os programas de formação docente devem colaborar para a construção do PCK dos futuros professores de ciências, abrindo espaço para que as peças-chave do conteúdo a ser ensinado sejam sujeitas à análise e discussão didática e pedagógica:

[...] Esse tipo de reflexão ajudaria os professores em formação a desenvolver seu PCK, como também a capacidade crítica e as habilidades analíticas que lhes permitiriam conceber a aula como um espaço de exploração e investigação contínua (TALANQUER, 2004, p.65, tradução nossa).

Basta analisar as decisões que um professor de química toma na sala de aula para poder reconhecer a natureza e complexidade do PCK que seu trabalho demanda.

Tais decisões estão ancoradas num conhecimento de conteúdo impregnado pedagogicamente que é incorporado ao professor na formação inicial e ampliado substancialmente na sua experiência de sala de aula. (TALANQUER, 2004) 


\section{CONSIDERAÇÕES FINAIS E IMPLICAC̣ÕES PARA A FORMAC̣ÃO DE PROFESSORES DE CIÊNCIAS}

A partir desse breve panorama da literatura acerca dos modelos sobre a base de conhecimentos e o PCK no ensino de ciências, percebem-se algumas concordâncias e divergências. Em relação à base de conhecimentos, todos os modelos concordam em incluir o conhecimento do conteúdo (ou ampliado como conhecimento do tema em alguns deles), o conhecimento pedagógico, conhecimento do contexto e o PCK. O conhecimento do currículo aparece como componente da base de conhecimentos no modelo inicial de Shulman (1986) e no de Morine-Dershimer e Kent (1999). Nos demais modelos, aparece como componente do PCK. O conhecimento dos estudantes e suas dificuldades aparece como pertencente à base de conhecimentos nos modelos de Shulman (1987), Morine-Dershimer e Kent (1999) e no de Rollnick et al. (2008), enquanto para os demais modelos aparece como um elemento do PCK. Alguns modelos, a partir da ideia de Grossman, enfatizam o papel do contexto (CARLSEN, 1999), enquanto outros focam no conhecimento pedagógico (MORINE-DERSHIMER; KENT, 1999). Em todos os modelos apresentados, o conhecimento do conteúdo é considerado um dos conhecimentos da base. Entretanto, esse tem sido um ponto de divergência se considerarmos outros modelos da literatura. Outras propostas diferem da ideia inicial de Shulman, incorporando o conhecimento do conteúdo ao PCK, como em Banks Leach e Moon (2005); Cochran, Deruiter e King (1993); Fernandez-Balboa, Stiehl (1995); Koballa et al., 1999; Marks, 1990; Veal; MaKinster, 1998.

Em relação aos modelos sobre o PCK, na proposta inicial de Shulman (1987), o conhecimento do conteúdo não estava incluído no PCK, mas era um dos sete conhecimentos base dos professores. Os modelos de Grossman (1990), de Magnusson, Krajcik e Borko (1999), de Carlsen (1999), de Abell (2008) e da cúpula do PCK seguem nessa linha, deixando o conhecimento do conteúdo externo ao PCK, sendo um dos conhecimentos da base.

Uma segunda distinção entre os modelos é a inclusão do conhecimento da avaliação e se este é parte da base ou do PCK. Os modelos iniciais de Shulman e Grossman não consideram o conhecimento da avaliação como um componente separado, muito embora possa estar inferido no conhecimento pedagógico. Assim, neste caso, Magnusson, Krajcik e Borko (1999) fizeram uma boa contribuição ao ensino de ciências incluindo esse componente. Após esses autores, outros modelos consideram o conhecimento de avaliação como um componente importante, apesar de divergirem se é um componente do conhecimento de base ou do PCK (TACOSHI; FERNANDEZ, 2014).

O modelo da cúpula do PCK revisita de alguma forma o modelo inicial de Shulman tanto em termos de PCK como em termos dos conhecimentos da base, focando no ensino de ciências, e incorpora novos elementos que foram contribuições de outros modelos apresentados. No modelo da cúpula, o conhecimento de avaliação, que tinha sido ignorado por Shulman e Grossman, pelo menos explici- 
tamente, é incorporado na base de conhecimentos. Além disso, concordando com a ideia inicial de Shulman, o conhecimento do currículo e dos alunos aparecem como conhecimentos da base dos professores de ciências. Nesse modelo o PCK retoma a ideia original de Shulman ao incorporar as estratégias instrucionais, as representações de conteúdo, a compreensão dos alunos e a visão de ciência.

O modelo da cúpula do PCK representa ainda o desenvolvimento do PCK com a prática em sala de aula e incorpora o papel das crenças de professores e alunos, levando também em conta o filtro do contexto. Assim, reafirma a ideia inicial de Shulman e Grossman e coloca o PCK novamente no centro da base de conhecimentos de professores. Por essas razões, esse modelo parece ter feito uma síntese das principais ideias discutidas, incorporando elementos de modelos anteriores e fazendo uma releitura das ideias originais de Shulman e Grossman para o ensino de ciências.

Independentemente das diferentes interpretações, a base de conhecimentos e o PCK têm sido considerados os melhores referenciais teóricos para analisar e compreender as competências dos professores de ciências, sistematizando os dados empíricos e possibilitando a documentação e troca de ideias sobre o conhecimento relevante para a prática docente (FERNANDEZ, 2011, 2014a, 2014b).

O modelo da cúpula é resultado de reflexões sobre dados empíricos de muitos grupos de pesquisa em ensino de ciências que analisaram professores em distintos níveis de ensino e em diferentes fases da vida profissional. Entretanto, ele não representa o modelo final e, com certeza, mais dados necessitam ser levantados com professores de ciências para que esse modelo possa ser validado e/ ou modificado. Até o momento, no entanto, é o modelo que mais se aproxima de explicar a prática da sala de aula e exerce assim o papel central de sistematizar os dados e facilitar as trocas entre diversos pesquisadores.

Investigações sobre os conhecimentos de professores de ciências nos diferentes momentos profissionais (formação inicial, estagiários, novatos e experientes) têm como principal objetivo fornecer subsídios para reformular currículos de formação de professores de ciências. Se a prática profissional dos bons professores puder ser acessada e documentada, pode, então, ser usada como um ponto de partida para professores inexperientes e, assim, ajudá-los em sua formação. Pode ainda fornecer elementos importantes para serem incorporados na formação inicial de professores de ciências.

Por outro lado, uma vez que existem diferentes maneiras de conceituar PCK e diferentes autores propõem diferentes modelos em que algumas habilidades são priorizadas em detrimento de outras, é importante estar atento e apresentar qual o modelo está sendo usado de forma que os resultados possam contribuir para o desenvolvimento de modelos teóricos já propostos.

Cursos de formação de professores de ciências devem considerar abrir espaço para que os licenciandos possam refletir sobre os conteúdos específicos, de modo que as peças-chave do conteúdo a ser ensinado sejam sujeitas à análise e discussão didática e pedagógica. Devem ainda considerar espaços em que a prá- 
tica de sala de aula possa ocorrer com objetivo de desenvolver o PCK. Para isso é fundamental promover o processo reflexivo ainda na formação inicial auxiliado pelos formadores e professores mais experientes. Sendo assim, o papel central da prática pedagógica e do processo reflexivo no desenvolvimento do PCK deve ser um ponto a ser considerado nas reformas curriculares de cursos de formação de professores de ciências.

\section{AGRADECIMENTOS}

A autora agradece o apoio financeiro para o grupo de pesquisa conduzido por agências governamentais brasileiras CNPq, CAPES e FAPESP CEPID Redoxoma, Processo N. 13/07937-8.

\section{REFERÊNCIAS}

ABELL, S. K. Research on science teacher knowledge. In: ABELL, S.K.; LEDERMAN, N.G., Handbook of research on science education. New York: Routledge, 2007. p. 1105-1149.

ABELL, S.K.. Twenty years later: Does pedagogical content knowledge remain a useful idea? International Journal of Science Education, London, v. 30, n. 10,

p. 1405-1416, 2008.

BANKS, F.; LEACH, J.; MOON, B. Extract from 'New understandings of teachers'pedagogic knowledge'. Curriculum Journal, London, v. 16, n. 3, p. 331-340, 2005.

BARNETT, J.; HODSON, D. Pedagogical Context Knowledge: toward a fuller understanding of what good science teachers know. Science Teacher Education, York, v. 84, n. 4, p. 426-453, 2001.

BAXTER, J. A.; LEDERMAN, N. G. Assessment and measurement of pedagogical content knowledge. In: GESS-NEWSOME, J.; LEDERMAN, N. G. (Eds.). Examining pedagogical content knowledge: the construct and its implications for science education. Dordrecht, The Netherlands: Kluwer Academic Publishers, 1999. p. 147-161.

CANDAU, V.M.F. Universidade e formação de professores: Que rumos tomar? In: CANDAU, V.M.F. (org.) Magistério, construção cotidiana. Petrópolis: Vozes, 1999. p. 30-50.

CANDAU, V.M.F. Rumo a uma nova didática. Petrópolis: Vozes, 2010, 184p.

CARLSEN, W. Domains of Teacher Knowledge. In: GESS-NEWSOME, J.; LEDERMAN, N. G. (Eds.) Examining pedagogical content knowledge: the construct and its implications for science teaching. Dordrecht, The Netherlands: Kluwer Academic Publishres, 1999. p. 21-50.

COCHRAN, F. K. DERUITER, J. A.; KING, R. A. Pedagogical content knowing: An integrative model for teacher preparation. Journal of Teacher Education, California, v. 44, p. 261-272, 1993.

CONNELLY, F. M.; CLANDININ, D. J. Personal practical knowledge and the modes of knowing: relevance for teaching and learning. In: EISNER, E. (Ed.). Learning and teaching the ways of knowing. Chicago: University of Chicago, 1985. p. 174-198.

DE JONG, O. et al. Exploring chemistry Teachers' Knowledge Base In: GILBERT, J.K. et al. Chemical Education: towards research-based practice. Dordrecht, The Netherlands: Kluwer Academic 
Publishers, 2002. p. 369-390.

ELBAZ, F. Teacher thinking: a study of practical knowledge. London: Croom Helm, 1983.

FENSTERMACHER, G. The knower and the known: the nature of knowledge in research on teaching. Review of Research in Education, California: AERA, n.20, p. 3-56, 1994.

FERNANDEZ, C. PCK - Conhecimento Pedagógico do Conteúdo: perspectivas e possibilidades para a formação de professores. In: VIII Encontro Nacional de Pesquisa em Educação em Ciências - ENPEC, Campinas, SP. Atas... Rio de Janeiro, RJ: ABRAPEC, v. 1. p. 1-12, 2011. Disponível em: <http://www.nutes.ufrj.br/abrapec/

viiienpec/resumos/R0370-1.pdf>. Acesso em: 3 mai. 2014.

FERNANDEZ, C. Knowledge base for teaching and Pedagogical Content Knowledge (PCK): some useful models and implications for teachers'training. Problems of Education in the Twenty First Century, Siauliai, Lithuania, v. 60, p. 79-100, 2014a.

FERNANDEZ, C.. A base de conhecimentos para o ensino e o Conbecimento Pedagógico do Conteúdo (PCK) de professores de Química. 2014. 329 f. (Tese de Livre Docência) - Instituto de Química, Universidade de São Paulo, 2014b.

FERNANDEZ, C.; GOES, L. F. Conhecimento pedagógico do conteúdo: estado da arte no ensino de ciências e matemática. In: GARRITZ, A. et al. (Org.). Conocimiento Didáctico del Contenido: Una perspectiva Iberoamericana. 1ed. Saarbrücken, Alemania: Editorial Académica Española, 2014. p. 65-99.

FERNÁNDEZ-BALBOA, J.M.; STIEHL, J. The generic nature of pedagogical content knowledge among college professors. Teaching and Teacher Education, California, v. 11, n. 3, p. 293-306, 1995.

FIORENTINI, D.; SOUZA JÚNIOR, A. J:; MELO, G. F. A. Saberes docentes: um desafio para acadêmicos e práticos. In: GERALDI, C.M.G. et al. (Orgs.). Cartografias do trabalho docente: professor(a) pesquisador(a). Campinas: Mercado de Letras, 1998. p. 307-335.

FREIRE, L. I. F.; FERNANDEZ, C. O professor universitário novato: tensões, dilemas e aprendizados no início da carreira docente. Ciência e Educaşão (UNESP. Impresso), v. 21, p. 255-272, 2015.

FREIRE, L. I. F;; FERNANDEZ, C. Professores novatos de química e o desenvolvimento do PCK de oxidorredução: influências da formação inicial. Educación Quimica, UNAM, México, v. XXV, p. 312-324, 2014.

FRIEDRICHSEN, P.; VAN DRIEL, J. H.; ABELL, S. K. Taking a closer look at science teaching orientations. Science Education, Hoboken, NJ, p. 358-376, 2010.

GAGE, N. L. Conference on studies in teaching; NATIONAL INSTITUTE OF EDUCATION, Washington, Panel 6. Teaching as clinical information processing, ERIC ED 111807, 65p., 1975.

GARRITZ, A.; TRINIDAD-VELASCO, R. El conocimiento pedagógico del contenido, Educación Quimica, UNAM, MéxicoLocal, v. 15, n. 2, p. 98-102, 2004.

GAUTHIER, C. et al. Por uma teoria da pedagogia: pesquisas contemporâneas sobre o saber. Ijuí, RS: Ed. UNIJUÍ, 1998.

GERALDI, W. A aula como acontecimento. Anais da Semana da Prática Pedagógica, Universidade de Aveiro, Portugal, CIFOP, 2003.

GESS-NEWSOME, J. Pedagogical Content knowledge: an introduction and orientation. In: GESS-

-NEWSOME, J.; LEDERMAN, N.G. (eds.) Examining Pedagogical Content Knowledge. Dordrecht, The Netherlands: Kluwer Academic Publishers, 1999. p. 3-17

GESS-NEWSOME, J.; CARLSON J. The PCK summit consensus model and definition of peda- 
gogical content knowledge. In: The Symposium Reports from the Pedagogical Content Knowledge (PCK Summit), ESERA Conference 2013, Nicosia, Cyprus, September, 2013.

GIROTTOO JR, G.; FERNANDEZ, C. Following early career chemistry teachers: the development of Pedagogical Content Knowledge from pre-service to a professional teacher. Problems of Education in the Twenty First Century, Siauliai, Lithuania, v. 55, p. 57-73, 2013.

GOES, L. F. Conhecimento Pedagógico do Conteúdo: estado da arte no campo da educação e no ensino de química. 155f. Dissertação (Mestrado em Ensino de Ciências), - Instituto de Química, Universidade de São Paulo, São Paulo, 2014.

GOES, L. F. et al. Aspectos do Conhecimento Pedagógico do Conteúdo de Química Verde em professores universitários de Química. Educación Química, UNAM, México, v. XXIV, p. 113-123, 2013.

GROSSMAN, P. L. The making of a teacher: teacher knowledge and teacher education. New York: Teachers College Press, 1990.

HELMES, J.; STOKES, L. A meeting of minds around Pedagogical Content Knowledge: designing an international PCK summit for professional, community, and field development. 2013. Disponível em: $<$ http://www.inverness-research.org/reports/2013-05_Rpt-PCK-Summit-Eval-final_03-2013. pdf>. Acesso em: 8 mai. 2014.

KIND, V. Pedagogical content knowledge in science education: perspectives and potential for progress. Studies in Science Education, Leeds, UK, v. 45, n. 2, p. 169-204, 2009.

KOBALLA, T.R. et al. Prospective teachers' conceptions of the knowledge base for teaching chemistry at the gymnasium. Journal of Science Teacher Education, New Yook, v. 10, n. 4, p. 269-286, 1999.

LANDAU, S.I. (org.). Cambridge Dictionary of American English for speakers of Portuguese: semibilingue ing/port. São Paulo: Editora WMF Martins Fontes, 2005.

LOUGHRAN, J. et al. Documenting science teachers' pedagogical content knowledge through PaP-eRs. Research in Science Education, New York, v. 31, n. 2, p. 289-307, 2001.

LOUGHRAN, J.; BERRY, A.; MULHALL, P. In search of pedagogical content knowledge in science: developing ways of articulating and documenting professional practice. Journal of Research in Science Teacbing, Hoboken, NJ, v. 41, n. 4, p. 370-391, 2004.

LOUGHRAN, J. ; BERRY, A.; MULHALL, P. Understanding and developing science teachers' pedagogical content knowledge. Rotterdam, The Netherlands: Sense Publishers, 2006.

MARCELO, C. El pensamiento del profesor. Barcelona: Ceac, 1987.

MARCELO, C.. La investigación sobre el conocimiento de los profesores y el proceso de aprender a enseñar. In: PERAFÁN G. A.; ADÚRIZ-BRAVO, A. Pensamiento y conocimiento de los profesores: debates y perspectivas internacionales. 2. ed., Bogotá: Editorial Nomos, 2005. p. 47-61.

MARKS, R. Pedagogical content knowledge: from a mathematical case to a modified conception. Journal of Teacher Education, California, v. 41, n. 3, p. 3-11, 1990.

MAGNUSSON, S.; KRAJICK, J.; BORKO, H. Nature, sources, and development of pedagogical content knowledge for science teaching. In: GESS-NEWSOME, J.; LEDERMAN, N. G. (Orgs.). Examining pedagogical content knowledge: the construct and its implications for science education. Dordrecht: Kluwer Academic Publishers, 1999. p. 95-132.

MONTENEGRO, V. L. S.; FERNANDEZ, C. Processo Reflexivo e desenvolvimento do Conhecimento Pedagógico do Conteúdo numa intervenção formativa com professores de Química. Ensaio: Pesquisa em Educação em Ciências [Online], Belo Horizonte, v. 17, p. 251-275, 2015. 
MORINE-DERSHIMER, G.; KENT, T. The complex nature and sources of teachers' pedagogical knowledge. In: GESS-NEWSOME, J.; LEDERMAN, N.G. (Eds.) Examining Pedagogical Content Knowledge. Dordrecht, The Netherlands: Kluwer Academic Publishers, 1999. p. 21-50.

NILSSON, P. Teaching for understanding: the complex nature of pedagogical content knowledge in pre-service education. International Journal of ScienceEducation, London, v. 30, n. 10, p. 1281-1299, 2008.

NOVAIS, R. M.; FERNANDEZ, C. A gestão da sala de aula de um professor do Ensino Superior. Campo Abierto, Badajoz, España, v. 33, p. 141-165, 2014.

NOVAIS, R. M.; FERNANDEZ, C. O acesso ao Conhecimento Pedagógico do Conteúdo de "Cinética Enzimática" de um professor do ensino superior a partir de narrativas sobre sua prática docente. Enseñanza de las Ciencias, Barcelona, v. Extra, p. 3801-3806, 2013.

OLIVEIRA-JR., M. M. Flashes das disciplinas de formação inicial no repertório profissional de licenciandos em química. 194 f. Dissertação (Mestrado em Ensino de Ciências), Instituto de Química, Universidade de São Paulo, São Paulo, 2011. Disponível em: <http://www.teses.usp.br/teses/disponiveis/81/81132/tde-30052012-145050/pt-br.php>. Acesso em: 2 jun. 2014.

PARK, S.; OLIVER, S. Revisiting the conceptualization of pedagogical content knowledge (PCK): PCK as a conceptual tool to understand teachers as professionals. Research in Science Education, New York, v. 38, p. 261-284, 2008.

PEREIRA, P. G. E. M.; FERNANDEZ, C. Indícios do modelo integrativo no desenvolvimento do PCK em licenciandos em química durante o estágio supervisionado. Revista de Educación de las Ciencias, Foz de Iguaçu, UNILA, v. 14, p. 74-78. 2013.

PIMENTA, S. G. (org). Saberes pedagógicos e atividade docente. São Paulo: Cortez, 2012. 296 p.

ROLDÃO, M. C. Função docente: natureza e construção do conhecimento profissional. Revista Brasileira de Educação, Rio de Janeiro v. 12, n. 34, p. 94-103, 2007.

ROLLNICK, M. et al. The place of subject matter knowledge in pedagogical content knowledge: a case study of South African teachers teaching the amount of substance and chemical equilibrium. International Journal of Science Education, London, v. 30, n. 10, p. 1365-1387, 2008.

SALAZAR, S. F. El conocimiento pedagógico del contenido como categoría de estudio de la formación docente. Actualidades investigativas en educación, Costa Rica, v. 5, n. 2, 2005. Disponível em: $<$ http://revista.inie.ucr.ac.cr/>. Acesso em: 2 jun. 2014.

SALES, M. G. P. Investigando o conhecimento pedagógico do conteúdo sobre "soluções" de uma professora de Química. 253 f. Dissertação (Mestrado em Ensino de Ciências) - Instituto de Química, Universidade de São Paulo, São Paulo, 2010. Disponível em: <http://www.teses.usp.br/teses/disponiveis/81/81132/ tde-21022011-155615/pt-br.php>. Acesso em: 3 jun. 2014.

SCHNEIDER, R .M.; PLASMAN, K. Science Teacher Learning Progressions: A Review of Science Teachers' Pedagogical Content Knowledge Development. Review of Educational Research, Thousand Oaks, CA , v. 81, n. 4, p.530-565, 2011.

SCHWAB, J. J. Structure of the disciplines: meanings and significances. In: FORD, G.W.; PUGNO, L. The structure of knowledge and the curriculum. Chicago: Rand McNally \& Company, 1964. p. 6-30.

SHULMAN, L. S. Those who understand: knowledge growth in teaching. Educational Researcher, Thousand Oaks, California, v. 15, n. 4, p. 4-14, 1986.

SHULMAN, L. S. Knowledge and teaching: foundations of a new reform. Harvard Educational Revien, Harvard, v. 57, n. 1, p. 1-22, 1987. 
SHULMAN, L. S. Foreword. In: GESS-NEWSOME, J.; LEDERMAN, N. G. (Eds.). Examining pedagogical content knowledge. Dordrecht. Kluwer Academic Publishers, 1999. p. IX-XII.

SHULMAN, L. S. Research on teaching: a historical and personal perspective. In: SHULMAN, L. S.. The wisdom of practice: essays on teaching learning, and learning to teach. San Francisco: Jossey-Bass, 2004. p. 364-381.

SILVA, A. N. Um professor de Quimica e dois contextos escolares: o conhecimento pedagógico do conteúdo em ação. 2012. 154f. Dissertação (Mestrado em Ensino de Ciências), Instituto de Química, Universidade de São Paulo, São Paulo, 2012. Disponível em: <http://www.teses.usp.br/teses/ disponiveis/81/81132/tde-25022013-132509/pt-br.php>. Acesso em: 3 jun. 2014.

TACOSHI, M. M. A.; FERNANDEZ, C. Knowledge of Assessment: an important component in the PCK of Chemistry teachers. Problems of Education in the Twenty First Century, Siauliai, Lithuania, v. 62, p. 124-147, 2014.

TALANQUER, V. Formación docente: Qué conocimiento distingue a los buenos maestros de química? Educación Química,México, v. 15, n. 1, p. 60-66, 2004.

TARDIF, M. Saberes docentes e formaģão profissional. 12ª Ed., Petrópolis (RJ): Vozes, 2010.

TARDIF, M.; LESSARD, C. O ofício de professor: história, perspectivas e desafios internacionais, 5. ed., Petrópolis, RJ: Vozes, 2013.

TARDIF, M. et al. Os professores face ao saber: esboço de uma problemática do saber docente. Teoria \& Educação, Porto Alegre: Pannônica, n. 4, 1991.

VAN DRIEL, J. H. et al. Developing science teachers' pedagogical content knowledge. Journal of Research in Science Teaching, Hoboken, NJ, v. 35, n. 6, p. 673-695, 1998.

VEAL, W. R.; MAKINSTER, J. G. Pedagogical content knowledge taxonomies. Electronic Journal of Science Education, Fort Worth, TX, 1998. Disponível em: <http://unr.edu/homepage/crowther/ ejse/vealmak.html>. Acesso em: 3 abr. 2012.

Data do Recebimento:17/04/2014

Data da Aprovação: 03/06/2015

\section{Contato:}

Carmen Fernandez

Av. Prof. Lineu Prestes 748, São Paulo SP - Brasil

Cep: 05508-000

E-mail: carmen@iq.usp.br

\section{ERRATA \\ doi.org/10.1590/1983-21172015170211er}

No artigo: Fernandez, Carmen REVISITANDO A BASE DE CONHECIMENTOS E O CONHECIMENTO PEDAGÓGICO DO CONTEÚDO (PCK) DE PROFESSORES DE CIÊNCIAS. Ensaio Pesquisa em Educação em Ciências (Belo Horizonte) [online]. 2015, v. 17, n. 2 [Acessado 22 Outubro 2021] , pp.500-528. Disponível em: <https://doi.org/10.1590/1983-21172015170211>. Epub May-Aug 2015. ISSN 1983-2117. https://doi.org/10.1590/1983-21172015170211.

Na página 518, onde se lê no cabeçalho do Quadro1. Instrumento CoRe - Representações do Conteúdo, a frase: Lista de funções criadas a partir das paráfrases.

\section{Desconsiderar a frase no cabeçalho.}

